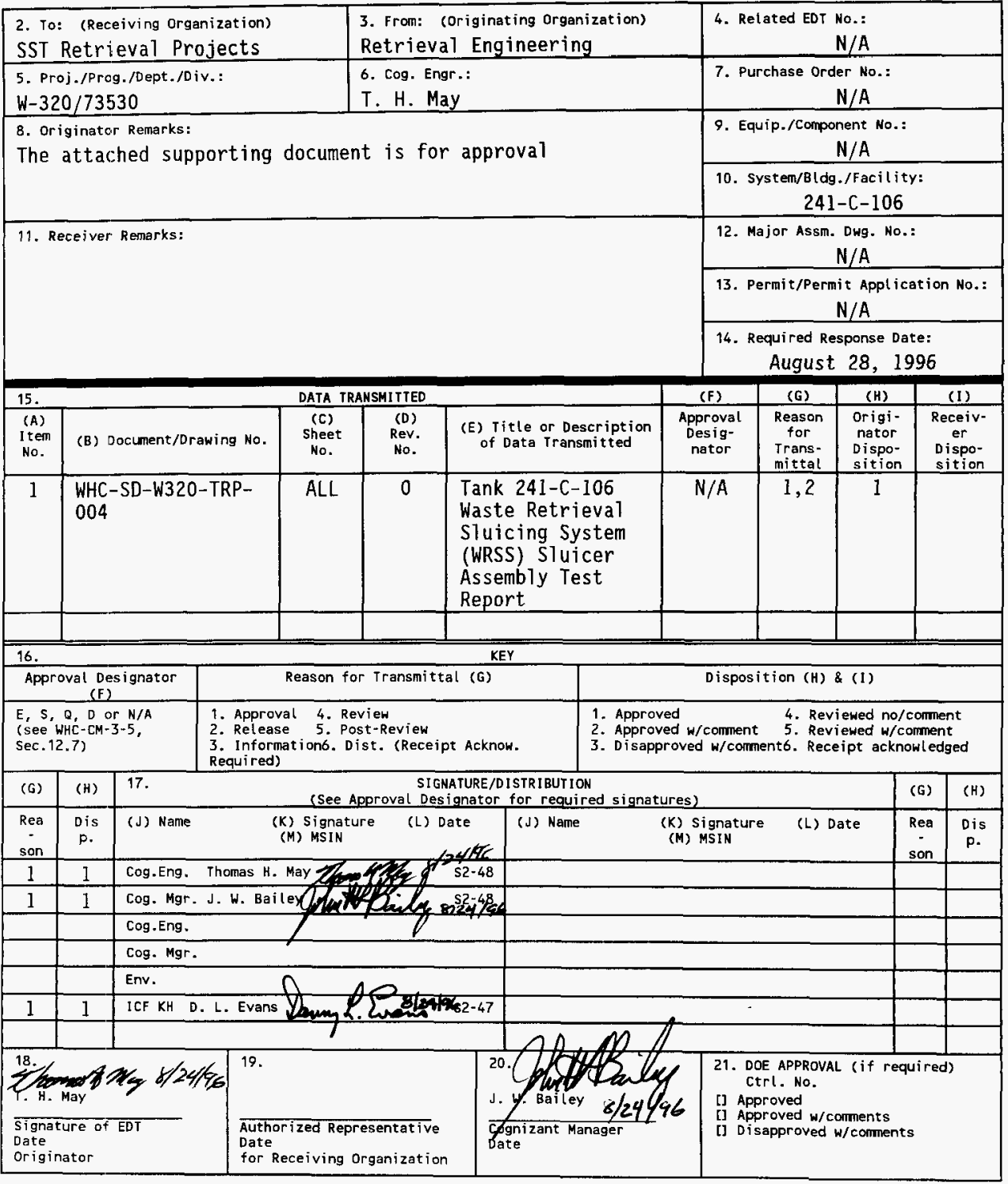




\section{TANK 241-C-106 WASTE RETRIEVAL SLUICING SYSTEM (WRSS) SLUICER ASSEMBLY TEST REPORT}

Thomas H. May

Westinghouse Hanford Company, Richland, Washington 99352

U.S. Department of Energy Contract DE-AC06-87RL10930

D. L. Evans

ICF Kaiser Hanford Company, Richland, WA 99352

U.S. Department of Energy Contract DE-AC06-87RL10930
EDT/ECN: 610539
UC: 2030
Org Code: 73530\&5A210
Charge Code: D2ME2
B\&R Code: EW3130010
Total Pages: $Y \&$ Can $\$ 2.6 / 2.5$

Key Words: SST, DST, C-106, AY-102, S7uicing, Past Practice Sluicing, Retrieva1, Sluicer, Sludge, High Heat Tank, Watch List Tank, Secretarial Initiative, and Waste Retrieval Sluicing System (WRSS).

Abstract: The sluicer test report documents the results of the Project W-320 factory testing conducted at the 0lympic Tool and Engineering facility. Included are background information, test goals, a brief discussion on the sluicer hose problem, and conclusions.

TRADEMARK DISCLAIMER. Reference herein to any specific commercial product, process, or service by trade name, tradenark, manufacturer, or otherwise, does not necessarily constitute or imply its endorsement, recommendation, or favoring by the United States Government or any agency thereof or its contractors or subcontractors.

Printed in the United States of America. To obtain copies of this document, contact: WHC/BCS Document Control Services, P.O. Box 1970, Mailstop H6-08, Richland WA 99352, Phone (509) 372-2420; Fax (509) 376-4989.
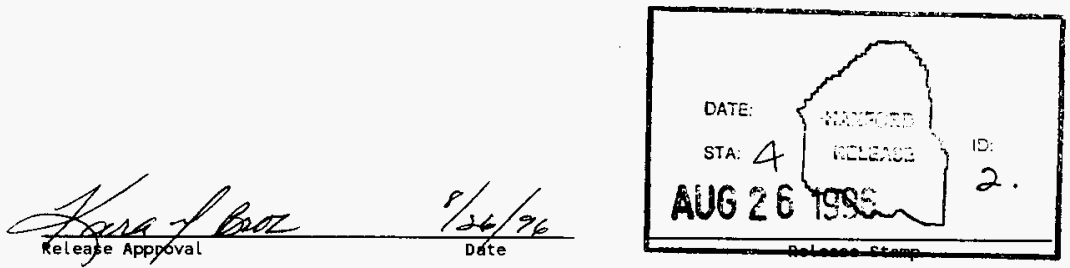

\section{Approved for Public Release}




\section{TABLE OF CONTENTS}

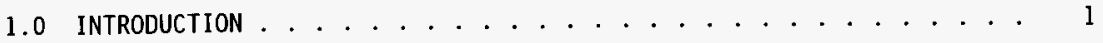

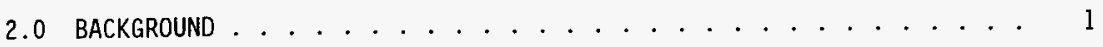

3.0 TEST GOALS AND OBJECTIVES ................... . . 1

4.0 SLUICER HOSE PROBLEM ................... . . 2

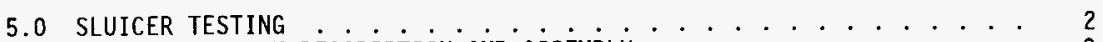

5.1 EQUIPMENT DESCRIPTION AND ASSEMBLY . . . . . . . . . . . 3

5.2 INITIAL SYSTEM TESTS . . . . . . . . . . . . . 3

5.3 CALIBRATION AND MANUAL TESTS .............. 3

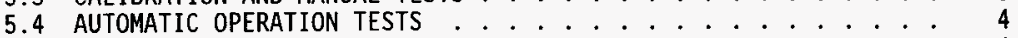

5.5 ENDURANCE TESTS ................... . . . . 4

5.6 HEAT DISSIPATION TEST . . . . . . . . . . . . . . . . . 4

5.7 HYDROSTATIC PRESSURE TEST . . . . . . . . . . . . . . . 4

6.0 CONCLUSIONS AND RECOMMENDATIONS .................... 4 
WHC-SD-W320-TRP-004

Revision 0

\section{PROJECT W-320, SLUICER ASSEMBLY}

TEST REPORT

\subsection{INTRODUCTION}

This test report documents the results of the integrated testing of the Project W-320 sluicer assembly. The sluicers are being fabricated in $01 y$ mpic Tool and Engineering in Shelton, Washington, in accordance with Procurement Specification W-320-P20 under Purchase Order \# MZ4-XDV-81340. The procurement specification for the sluicer assemblies requires factory acceptance testing (FAT) of the fabricated equipment to demonstrate compliance with the equipment specifications and to verify the adequacy of the design. This testing was conducted at the Shelton facility during the following periods: June 6 and 7 , 1996 , June 20 and 21, 1996, for the primary sluicer (S-1361); and August 5 and 6,1996 , for the secondary sluicer. Project representatives witnessing testing included T. H. May (Westinghouse Hanford Company $[W H C]$ ), T. K. Cordray (WHC), and D. L. Evans (ICF Kaiser Hanford Company [ICF-KH]). This summary of the sluicer test includes background information, the test goals, a brief discussion of hose problems, a detailed discussion of the test itself, and conclusions and recommendations.

\subsection{BACKGROUND}

Project $W-320$ was established to remove and transport radioactive and chemical sludge from single-she11 tank 241-C-106 to double-shell tank 241-AY-102. Techniques that were successful in earlier waste retrieval campaigns will be used to remove the waste from the tanks. All equipment, components, and infrastructure needed to conduct sluicing operations are provided as part of the project. This includes design, procurement and fabrication, and installation and testing of the following components: A sluicer, immersible and in-line slurry and sluice pumps, winch assemblies, waste transfer lines, a new HVAC system at tank 241-C-106, air, water, and fire protection systems at C-Farm, and electrical upgrades at both the $\mathrm{C}$ - and AY- tank farms.

The sluicer will extend inside waste tank 241-C-106 through sluice pit 241- $\complement-06 C$ riser number 3 . The sluicer directs the sluice stream at the waste. Hydraulic controls provide the mechanical means for remote pan and tilt positioning of the sluicer nozzle.

Two sluicers and hydraulic controls are being fabricated and tested by an offsite vendor. Only one slucier will be installed in 241-C-106 unless the waste is more difficult to sluice than anticipated.

\subsection{TEST GOALS AND OBJECTIVES}

The primary objective of the sluicer test were to verify that the sluicers functioned properly and could be operated as designed under simulated operating conditions. Specific test goals were as follows: 
WHC-SD-W320-TRP-004

Revision 0

- Demonstrate manual and semi-automatic operation of the system

- Demonstrate maximum sweep speeds (i.e., 6 degrees per second)

- Record position indication versus actual measured nozzle position

- Prove leak tightness of the hydraulic system

- Demonstrate freedom of motion of the hydraulic and electrical cables during sluicer rotation

- Demonstrate adequate heat dissipation of the hydraulic system under maximum lead (maximum by-pass) conditions

- Demonstrate 4 hours of continuous operation in the semi-automatic mode

- Develop videotapes to support personnel training and the operational readiness review process.

\subsection{SLUICER HOSE PROBLEM}

The primary sluicer was initially fabricated with Gates Rubber Co. Food Master $^{R}$ Industrial hose rated for 250 PSI. This hose was selected because it could be fabricated with 4 -in. stainless steel extended body internally expandedferrules to ensure that the sluicer would fit down the riser. During the hydrostatic pressure test on June 6 , the hose deflected significantly and pulled loose from the ferrule, releasing water and dropping the pressure. A vendor search located an 800-psi Titan SS-11l high-pressure jetting hose that could use the same size ferrule. The new hose actually shrank slightly under pressure and easily passed the hydrostatic test. Testing on the secondary sluicer did not experience any of these problems.

\subsection{SLUICER TESTING}

The FAT consisted of the following tests:

1. Initial system tests

2. Calibration and manual tests

3. Automatic operation tests

4. Endurance tests

5. Heat dissipation test

6. Hydrostatic pressure test.

The test sequence was videotaped by the members of the project team witnessing testing. Videotapes of testing are available for review and will be retained as part of the project files. Results of the tests are detailed in vendor submittals filed in Certified Vendor Information Number 22668. 
WHC-SD-W320-TRP-004

Revision 0

\subsection{EQUIPMENT DESCRIPTION AND ASSEMBLY}

The equipment subjected to testing during the sluicer tests included the 241-C-106 sluicer (S-1361) and the sluicer hydraulic control (SHC-1361). Figure 1 is a diagram of the sluicer. The sluicer was tested in the horizontal position during the FAT. The sluicer was tested dry, without sluicing fluid flowing through the nozzle.

\subsection{INITIAL SYSTEM TESTS}

These tests were performed to determine that no serious engineering or assembly errors occurred that could prevent operation. No problems were noted. Testing verified that electrical cabling and hydraulic hoses could not be cross connected. Testing proved that the load holding valve was properly adjusted to provide smooth movement in both directions. During the June 6 test the following problems arose.

- The hydraulic control on the tilt was unbalanced across the dualacting cylinder. This resulted in an unacceptable drift of $2^{\circ}$ per minute. The hydraulic vendor substituted a different-style control valve and the problem disappeared.

- The hydraulic fluid temperature and level switch did not work, but it was replaced and later demonstrated successfully.

\subsection{CALIBRATION AND MANUAL TESTS}

During these tests, the tilt and pan sweep rates were set, the full stroke travel was checked, and accuracy of nozzle positioning was tested. Tilt and pan sweep rates were initially faster than $7^{\circ}$ per second, but the rates were reset to $5^{\circ}$ per second. This was done by adjusting the hydraulic fluid control valves and measuring the sweeps with inclinometers attached to the sluicer. Sweep rate can be set repeatably to $5^{\circ}$ per second because the adjustment knobs have colored rings on the stems; each ring corresponds to one revolution. The required setting is one 0.75 revolution from full closed, which uncovers the green ring with the orange ring just beginning to show. Full stroke travel for pan and tilt was checked and matched the required values of $\pm 97^{\circ}$ pan, $+90^{\circ}$ up, and $-40^{\circ}$ back.

Accuracy of nozzle positioning was measured because a $1^{\circ}$ variance in nozzle positioning at the far end of the tank will result in a $0.3-\mathrm{m}$ (l-ft) error. An operator expecting to be at the edge of the $1.5 \mathrm{~m}(5-\mathrm{ft})$ "no-sluice zone"could be 20 percent into the zone with the error. This could inadvertently direct the sluicing stream at the pump. An accuracy of $\pm 0.3^{\circ}$ was demonstrated for both ZE/ZT/ZI-13613 and ZE/ZT/ZI-13614. This was determined to be acceptable.

The sluicer hydraulic control unit (SHC-1361) reservoir was equipped with level (LSL-1362) and temperature (TSH-1362) switches by the vendor. The hydraulic control unit is a packaged assembly. A functional test was performed and verified that the switches work. 
WHC-SD-W320-TRP-004

Revision 0

\subsection{AUTOMATIC OPERATION TESTS}

Full-stroke setpoints were set at meter ZI-13614 and the sluicer was allowed to traverse a full stroke and automatically reverse and sweep back. This was continued long enough to demonstrate the sluicer in automatic mode.

\subsection{ENDURANCE TESTS}

An endurance test was performed for 4 hours for each sluicer with no problems occurring. A pressure of 200 psi was maintained in the sluicer. With the tilt set at $90^{\circ}$, the sluicer was allowed to pan from $\pm 95^{\circ}$ for 2 hours. Periodic readings of the inclinometer indicated no significant drift. The tilt was then set at $-40^{\circ}$ and the sluicer was allowed to pan from $\pm 15^{\circ}$ for 2 hours. Periodic readings of the inclinometer indicated no significant drift. During these tests, no hydraulic fluid leaks were detected, and the sluicer operated smoothly.

\subsection{HEAT DISSIPATION TEST}

Before the June 6 tests began, the sluicer controls were shut down for 2 hours while the hydraulic supply unit (SHC-1361) continued to run. The hydrautic reservoir temperature increased to $57^{\circ} \mathrm{C}\left(135^{\circ} \mathrm{F}\right)$ and was shut down automatically by the temperature interlock. The ambient temperature was $18{ }^{\circ} \mathrm{C}$ $\left(65{ }^{\circ} \mathrm{F}\right)$. Later it was discovered that the incorrect temperature switch had been installed and the correct one was substituted. During the endurance test, the temperature of the reservoir increased to $58^{\circ} \mathrm{C}\left(137^{\circ} \mathrm{F}\right)$, which did not shut the unit down. The hydraulic supply unit is rated to operate at $71{ }^{\circ} \mathrm{C}\left(160^{\circ} \mathrm{F}\right)$.

\subsection{HYDROSTATIC PRESSURE TEST}

A hydrostatic pressure test determined that the basic sluicer piping is sound and free from leaks and defects. The nozzle was removed and replaced with a cap. Pressure was increased to $480 \mathrm{psig}$ in increments while measuring hose deflection. No leakage was detected and the hose did not deflect significantly.

\subsection{CONCLUSIONS AND RECOMMENDATIONS}

The testing showed that the sluicer assembly in its present configuration can perform its intended function. Although several problems were identified, no major problems were discovered that could be considered significant. Several items were noted during testing that will require further evaluation and/or correction. The following actions were recommended the sluicer assembly is installed in the waste tanks.

- Place a label on the joystick to indicate up/down/right/left.

- Mark or color code the rotating plate and the pinion gear to make proper alignment easily discernable. 
WHC-SD-W320-TRP-004

Revision 0

- Align the sluicer $0^{\circ}$ position with the tank center instead of due north as is presently designed.

ECN-W320-445 has been generated to modify the sluicer assembly in accordance with the recommendations noted above. 01ympic Tool and Engineering has also been directed to proceed with the recommended modifications. 
WHC-SD-W320-TRP-004

Revision 0

Figure 1. Waste Retrieval Sluicing System Sluicer.

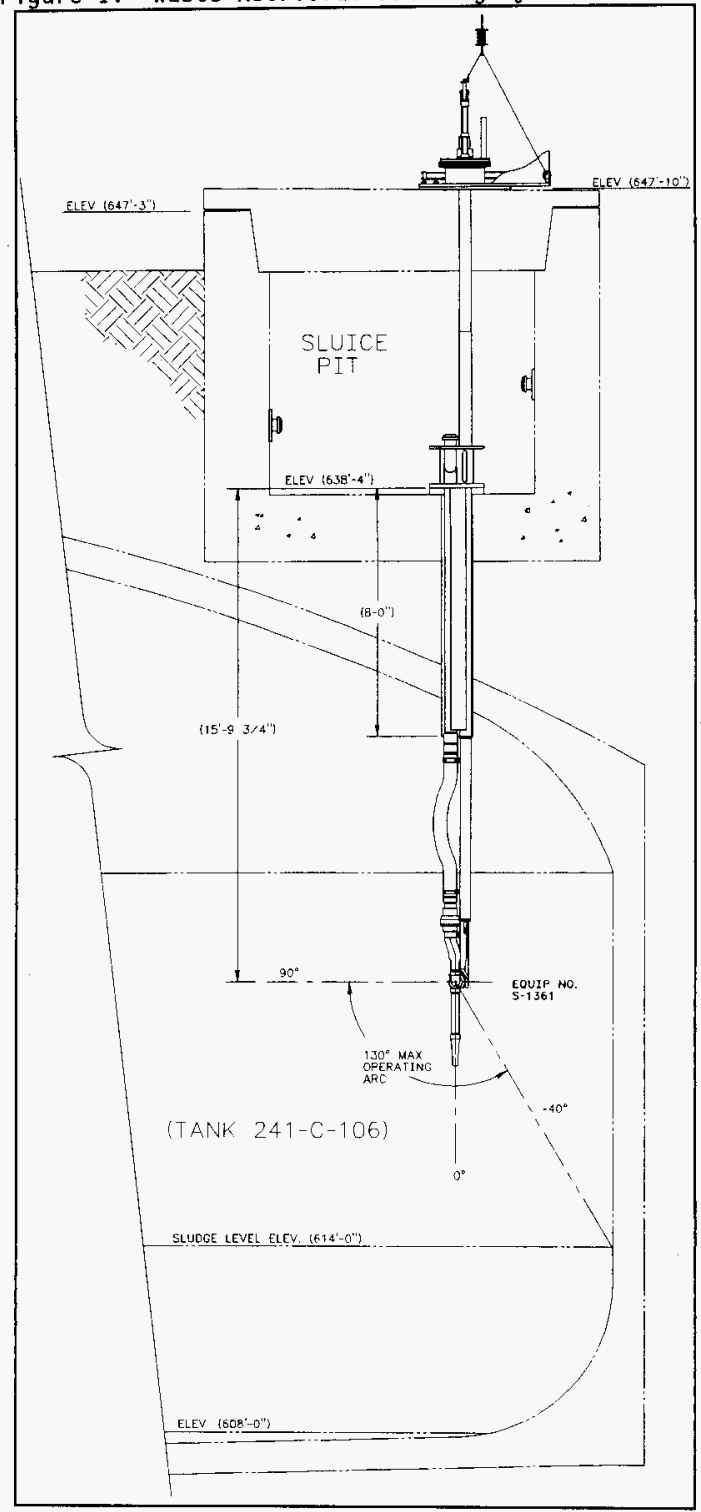




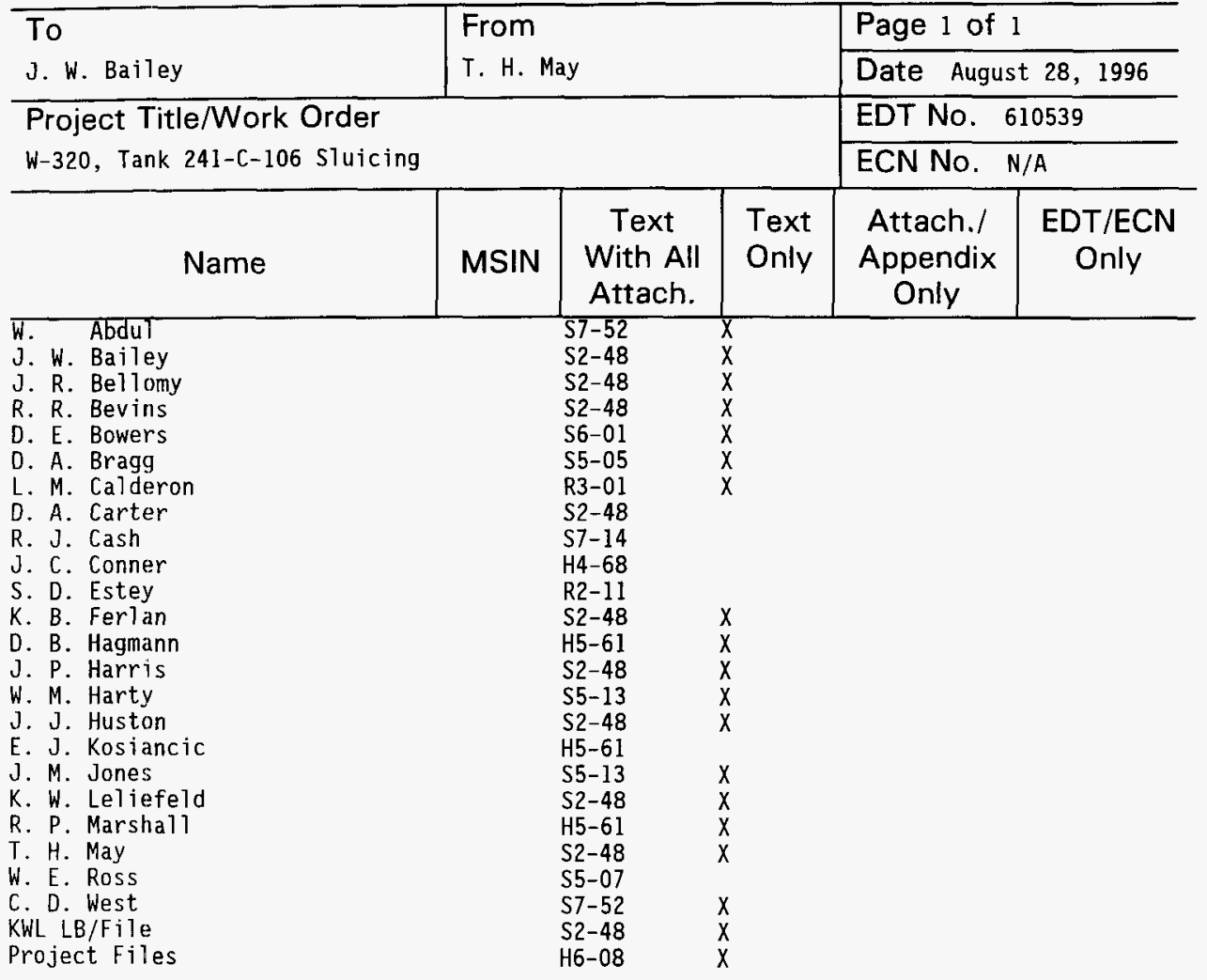

